\title{
Based on the Structural Mechanics of Dump Truck Chassis Frame of Design Improvement
}

\author{
ZhanGuo Wei* and ZhuoXian Zhou
}

Central South University of Forestry \& Technology, Hunan, 410004, China

\begin{abstract}
EQ3090 dump truck in the basis of EQ1090 modification and become, the chassis choose EQ1090 chassis. The modification of the main frame, including the main frame of the drilling and welding, the main frame of extension design, main frame of reinforcing plate design. Auxiliary frame modified, include the auxiliary frame of the cross section shape and size, reinforcing plate decorate, deputy frame front shape and installation location, rail and beam connection design, auxiliary frame and the main frame connection design, and finally, the auxiliary frame in intensity. The refit vehicle meet the using performance and achieve the anticipated goal.
\end{abstract}

Keywords: Dump truck, strength calculation, structural mechanics.

\section{INTRODUCTION}

EQ3090 car is a kind of multifunctional dump truck, its structure is shown as shown in Fig. (1). At present, the modification special purpose vehicle chooses chassis is mainly type or three kinds of automobile chassis, has some special purpose vehicle design special chassis. Automobile chassis choice or special chassis design according to the special purpose vehicle type, usage, loading quality, use condition, special purpose vehicle performance index, special equipment or device appearance size, power matching, etc. to decide.

In China, conventional van, tank truck, dump truck, etc. usually with type automobile chassis design modification. This is the special purpose vehicle design choose chassis type a kind of most. The so-called type automobile chassis, which is, namely, in the basis of fundamental vehicle. Remove the container. In the modified design of general arrangement, in no case car chassis, the required working device or special body. The second automobile chassis modified design work focuses on the general arrangement and working device design. In the design of the vehicle if strictly control the total quality, the quality of axle load distribution and mass center height position and so on, is basically can keep the original models of the main performance [1]. But, but also to the vehicle modified to make performance analysis and calculation.

For buses, notchback, van, etc. usually uses three kinds of automobile chassis design modification. The so-called three kinds of automobile chassis, is the basis of the car, getting rid of the containers and the bridge. In recent years, Chinese passenger car industry is developing, for passenger cars using performance requirements are constantly improving, then use the original three kinds of automobile

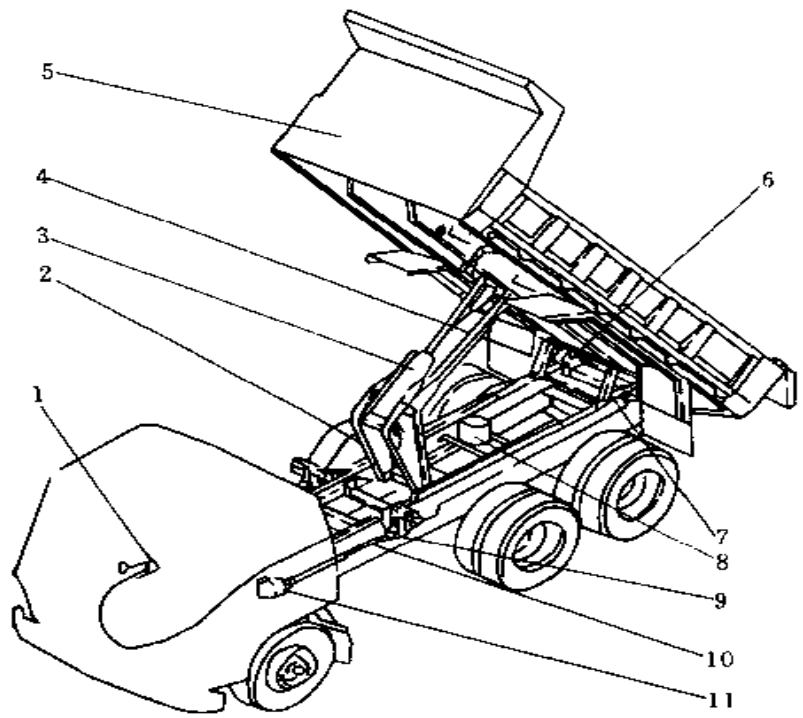

1 - hydraulic dump control device; 2 - dumping mechanism; 3 - hydraulic oil cylinder; 4 - rod; 5 - car; 6 - hinge support; 7 - safety strut; 8 - mail; 9 oil pump; 10 - drive shaft; 11 - power takeoff

Fig. (1). EQ3090 dump truck structure.

chassis refit car already more and more unpopular. Therefore, all kinds of special bus chassis arise at the historic moment. These special bus chassises are in the use of the basic characteristics of basic assembly, according to passenger car performance requirements updates the arrangement of the whole car, update the design suspension system. The chassis is not only in the centroid position, the vehicle performance especially comfort has changed a lot, but also in the drive system and dynamic matching, as well as the braking system of assembly also have a bigger modification design [2].

Currently in use common automobile chassis for modification design. The replacement of the engine chassis, such as gasoline engine change into a diesel engine. Also as three types of chassis processing [3]. 
No matter choose the type or three kinds of automobile chassis, it is difficult to fully satisfy some special purpose of vehicle performance requirements. For example, using common automobile chassis refitting van, the existing high center of mass, axle weight distribution is not reasonable. Modified fire truck, first is chassis speed constitute no requirements. Refit the guest van special vehicle, there is the comfort of the poor. Therefore, it can be said that if you want to make China's special purpose vehicle with the quality, grade, must develop some has the characteristics of special purpose vehicle chassis.

In the special purpose vehicle chassis or assembly type selection, the general should meet the following requirements:

\subsection{Applicability}

To freight vehicles assembly should adapt to the freight requirements, ensure freight safety condition; For passenger cars with assembly should be suitable for the needs of passengers. To take a safe and comfortable; To all sorts of special vehicle assemblies shall be suitable for special purpose vehicle special functional requirement, and takes it as a main target modified type design, such as various power takeoff output interfaces, etc.

\subsection{Reliability}

Chooses the assembly work should be reliable, the malfunction probability less, spare parts to have enough strength and life, and the same models the assembly parts life should tend to balance.

\subsection{Advanced}

Chooses chassis or assembly. Should make the vehicle with the power, economy and brake, control stability, riding comfort and through the sexual basic performance index and function aspects reach the advanced level of similar models. And in a special performance to meet the requirements of the national or trade standards.

\subsection{Convenience}

Chooses the assembly to facilitate installation, inspection, maintenance and repair. Deal with compact structure and assembly debugging space reasonable contradictions. In selecting special purpose vehicle chassis, besides the above factors outside, and the following two important aspects: one is the automobile chassis price [4], it is special purpose vehicle acquisition cost little is about part, must take into account the user can accept. It also relates to the special purpose vehicle product can quickly build market, enterprise can increase benefit problem. The second is automobile chassis supply should have sources, will be with the production automobile chassis we have a clear agreement or contract, regardless of the automobile chassis slow-moving or spruce, must on time will supply chassis.

In this paper the design EQ3090 dumper is on the basis of EQ1090 modification and become, so its chassis choose EQ1090 chassis.

\section{THE MAIN FRAME OF THE MODIFICATION}

The main frame is automobile chassis on the assembly and special work device installed base, the modification were worst affected, therefore, to special attention.

\subsection{Main Frame of Drilling and Welding}

The main frame is affected by various elements, only if been tested under static load, and under the vehicle dynamic load, in order to maintain the main frame of the strength and stiffness. Drilling and welding on the main frame girder is rejected in principle, unless frames were installed on the original holes. When special equipments or accessories were installed, and actions like drilling or welding have to carried, those high stress areas should be minded. The high stress area of the main frame girder is in between the wheelbases, it is in the beam below or above the rear suspension. And in these parts, girder stress is large, and drilling will produce stress concentration easily [5].

For the main frame girder high stress zone other than the rest of the place need drilling or welding, we should pay attention to the following matters:

To minimize holes, or to increase the distance in between, and positions and aperture standard, should meet requirements in Fig. (2) and Table $\mathbf{1}$.

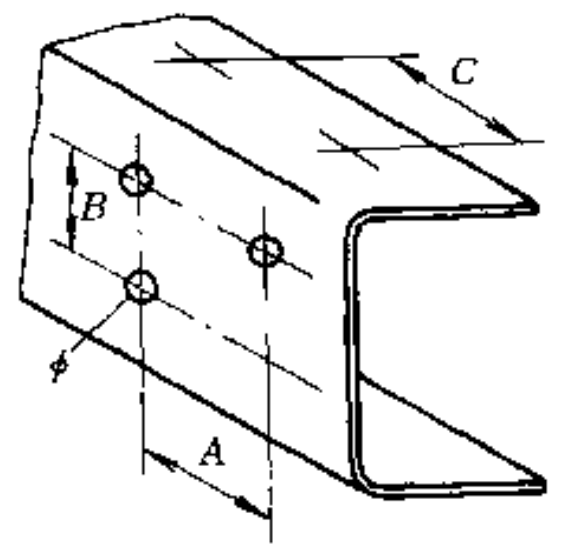

Fig. (2). Main frame drilling aperture and hole spacing.

Table 1. Main frame hole size requirements.

\begin{tabular}{|c|c|c|c|c|}
\hline \multirow{2}{*}{ Size } & \multicolumn{3}{|c|}{ Models } \\
\cline { 3 - 5 } \multicolumn{2}{|c|}{} & Heavy Car & Medium Car & Small Car \\
\hline \hline \multirow{3}{*}{ Hole distance/mm } & A & $>70$ & $>60$ & $>50$ \\
\cline { 2 - 5 } & B & $>50$ & $>40$ & $>30$ \\
\cline { 2 - 5 } & C & $>50$ & $>40$ & $>30$ \\
\hline Hole diameter/mm & $\Phi$ & $<15$ & $<13$ & $<11$ \\
\hline
\end{tabular}

1) In the longitudinal beam wing surface high stress area other parts of the drilling, only in the center of drill a hole, as shown in Fig. (2).

2) On the side of the girder, angled area also banned drilling or welding, as shown in Fig. (3). In Fig. (4), area which is not allowed drilling and welding either. 
When drill or weld in these parts, it is extremely easy to cause frame early cracking.

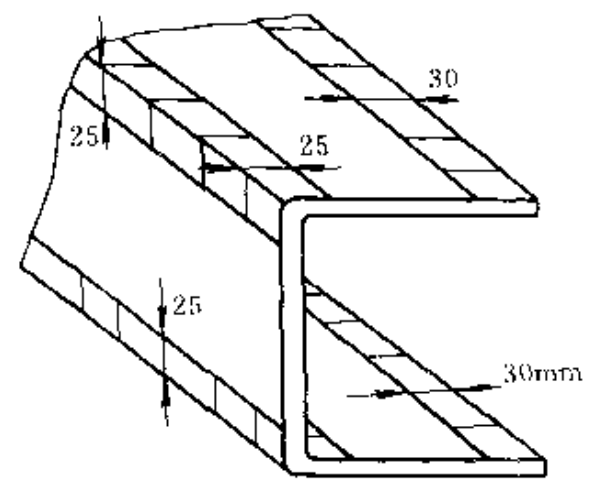

Fig. (3). Main frames girder ban drilling area.

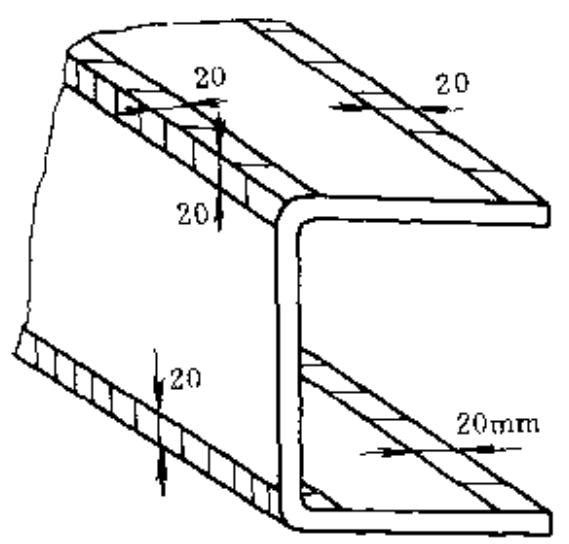

Fig. (4). Main frame girder banned weld zone.

This topic because of main frame and auxiliary frame the connection between the selection of thrust connection plate form, where to drill on the main frame could be ignored, only need to consider welding position properly.

\subsection{The Main Frame of Extension Design}

Because of the special purpose of what vehicle arrangement required, the main frame sometimes must carry on the extension. Such as van less-than-one carload transport vehicle and small goods transporter, if use general automobile chassis modification, we need to increase wheel base, modify long cargo compartments to improve transportation efficiency, but the frame will off central after the extension. Also will frame hanging part after extended modified design.

Frame extension parts should follow the original frame girder size specifications, with likely material performance. Extension parts and frame connectted generally by welding. First in the rail web place, to press longitudinal beam axis into $45^{\circ}$ or $90^{\circ}$ angle of the longitudinal beam direction off, and then cut a section processed into groove shape. Finally processing part and frame girder will butt up. In order to obtain $\mathrm{v}$ weld butt joint in best strength, before welding starting point appear welding defects, lead arc welding method or back arc welding method should be used. Welding should based on the girder material selection with suitable electrode model, diameter and welding specification [6].
Manual arc solitary welding, gas shielded welding and choose magnetic electrode are optional, which will prevent deformation and vibration under the condition of the welding strength.

\subsection{Main Frame Reinforcing Plate Design}

\subsubsection{Main Frame Girder Reinforcing Plate}

Purpose of main frame modification, is to reduce the local stress of frame girder, making sure that frame or extended parts can satify the intensity and the rigidity requirement, as loading quality increased. Wheel base and general changes, the frame to the central splicing or tail extension; In order to ensure the high stress area of frame(dangerous section) satisfy the intensity and the rigidity requirement, at the same time make frame in a certain interval of section size change apporpriated, these circumstances, often in the frame girder is reinforcing plate.

\subsubsection{Strengthening the Plate Shape}

Reinforcement plate of the cross section shape recommends $\mathrm{L}$, its thickness should be not less than $40 \%$ of the frame. L reinforcement plate of hebei surface should be coated on frame girder wing surface by the side of the stretch. Strengthen the end of plate shape should be gradually transitted, such as cut into less than $45^{\circ}$ angle, or in the end the central open smooth slot, as shown in Fig. (5).

\subsubsection{Strengthening the Arrangement of the Plate}

Laying out reinforcing plate reasonable, can reduce the frame stress effectively. If place it unreasonable, the frame may produce stress concentration. To avoid the stress concentration of the plate to strengthen the end position, plate should not be put in the stiffness-changing position and load concerntraded place. For example, we should intensify the end of plate and the end of auxiliary frame sufficient overlaps part or make both leave enough distance, as shown in Fig. (6).
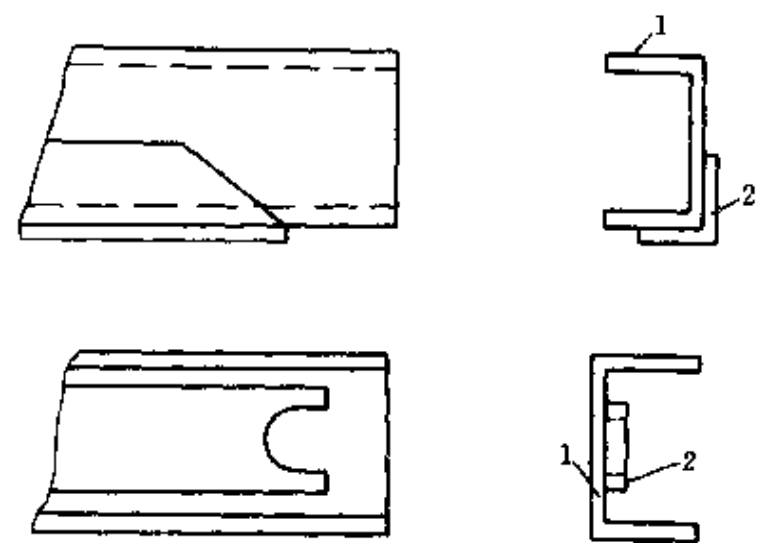

1 - main frame girder; 2 - reinforcing plate

Fig. (5). Reinforcement plate of turbulent head shape.

\subsubsection{To Strengthen the Control of Plate}

Reinforcing plate and fixing the main frame had better use riveting. Miniumn distance between reinforcing plate end and rivet hole is $25 \mathrm{~mm}$, rivet spacing for $70 \sim 150 \mathrm{~mm}$. 
When riveting have its difficulty, plug welding longitudinal beam glue board can be processed in reinforceing plate, diameter of plug weld hole is $20 \sim 30 \mathrm{~mm}$, minimum distance of plug weld hole and reinforcing plate end is $25 \mathrm{~mm}$, hole spacing is $100 \sim 170 \mathrm{~mm}$.

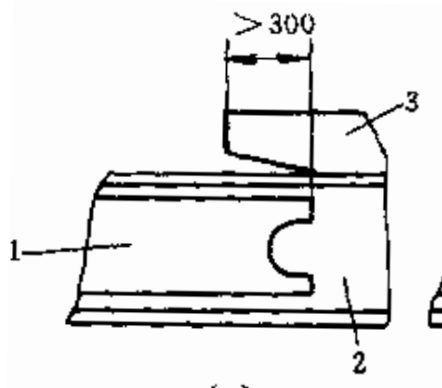

(a)

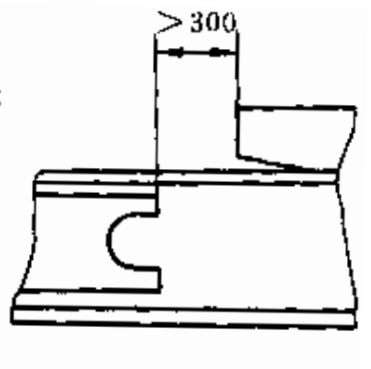

(b)
1 - reinforcing plate; 2 - main frame girder; 3 - auxiliary frame

Fig. (6). Reinforcing plate reasonable decorate.

\section{AUXILIARY FRAME DESIGN}

In special purpose vehicle design, in order to improve bearing of the main frame while avoid concentrated load, also not to damage the structure of main frame, generally use the auxiliary frame (deputy beam) transition. Default in the work by large bending stress. Therefore, the local auxiliary frame girder by using two root bending performance is good straight slot line beam, materials for $16 \mathrm{MnReL}$.

As auxiliary frame is incresed at the same time, in order to avoid the auxiliary frame stiffness change sharply and cause the stress concentration on the main frame, so the shape of auxiliary frame, installation position and the main frame connection mode have certain requirements.

\subsection{Auxiliary Frames of the Cross Section Shape and Size}

Shape of special purpose vehicle auxiliary frame cross section and main frame girder section are similar, as shown in Fig. (7), which is the channel structure, the section shape and size depend on the special purpose vehicle kinds and the size of the load. Taking derrick truck vice frame for example, in installation lifting device range, auxiliary frame section should pressed and closed as what shown in Fig. (8), to improve the auxiliary frame of the torsional and flexural capacity.

After referring to similar models of auxiliary frame girder end size at home and abroad, we determine the auxiliary frame girder end size as 100, 80, $6 \mathrm{~mm}$.

\subsection{Reinforcing Plate Decorate}

Central frame suffers the largest (hydraulic lifting mechanism position) bending and torsion, so reinforcing plate should added in this area. Considering the part manufacturability, due to the bending stress is increased on heavy wing plate, therefore, reinforcing plate should placed under close to wing, in order to avoid the bending strength decreased of wing plate due to boring hole, and in addition to strengthen plate overlap parts, this reinforcing plate main and web connection.
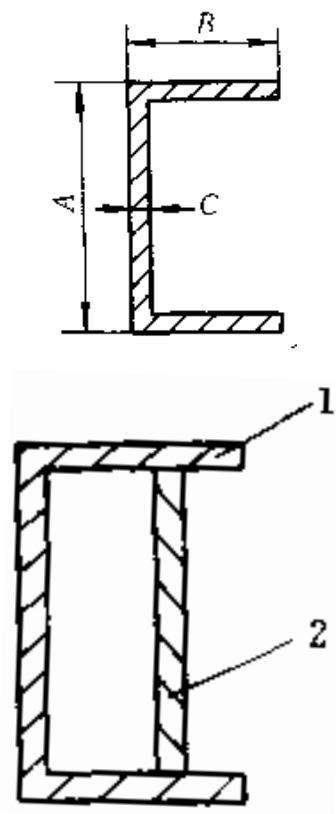

Fig. (7). Auxiliary frame of the cross section shape. 1 - auxiliary frame; 2 - web.

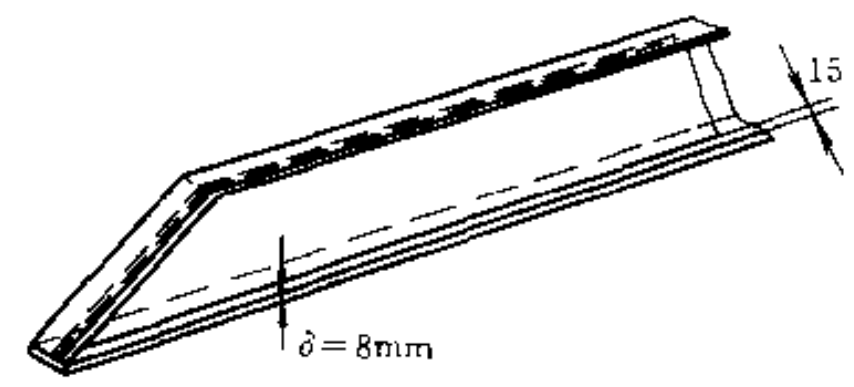

Fig. (8). After strengthening the auxiliary frame cross section shape. Strengthen the position of the web.

In the girder with reinforcing plate, reinforcing plate end area frame is easy to produce stress concentration. In order to reduce stress concentration, reinforcing plate end shape has three design optionals, see Fig. (9).

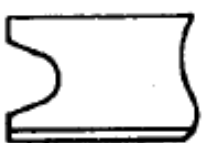

(a) U;

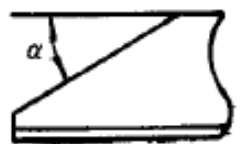

(b) Angle type;

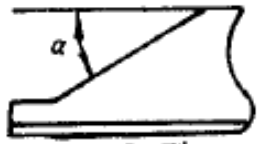

(c) L;
Fig. (9). Reinforcement plate of three kinds of design way.

This auxiliary frame in order to batch production process simple, the Fig. (10b) Angle type end shape.

\subsection{Auxiliary Frame the Front End of the Shape and Location}

1) When reliable premise is guaranteed, in order to improve the flexural resistance and reduce auxiliary frame rigidity, auxiliary frame beam will be reduced, 
and the torsional constraint of longitudinal beam will decreased too.

2) Auxiliary frame oil cylinder bearing beam and double shaft beam format framework. Oil cylinder bearing beam should be close to the suspension in the former of supporting beam, best can after is located in the framework. Because this gap of main frame deformation is small, so the auxiliary frame on the torsional binding also corresponding abate, at the same time guarantee the geometry characteristic of the lifting mechanism.

3) In the auxiliary frame structure, rigid requirements higher, but in the main, auxiliary frame intermediate increase a layer of rubber pad. when the main frame deformation with elastic deformation of the rubber to weaken the secondary frame for main frame constraints [7].

Auxiliary frame front shape often have three kinds of shapes, as shown in Fig. (10).

For the three different shapes of the auxiliary frame front end, in its and the main frame girder phase contact wing surface processing of a local slope, the oblique and size as shown in Fig. (10c) shows: $\mathrm{h}_{0}=1 \mathrm{~mm} ; \mathrm{l}_{0}=15 \sim 20 \mathrm{~mm}$.

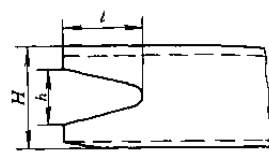

(a) U;

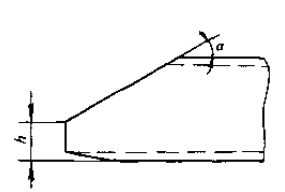

(b) Angle type;

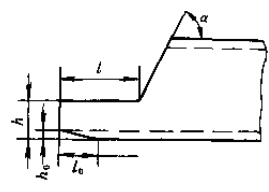

(c) $\mathrm{L}$
Fig. (10). Auxiliary frame of three kinds of front shape.

If processing the above shapes are difficult, what can be used are shown in Fig. (11), which shows vice frame front simple shape.

For steel auxiliary frame: $\mathrm{h}_{0}=5 \sim 7 \mathrm{~mm} ; 1_{0}=200 \sim 300$ $\mathrm{mm}$

For hard essence auxiliary frame: $\mathrm{h}_{0}=5 \sim 10 \mathrm{~mm} ; \mathrm{l}_{0}=\mathrm{H}$;

Auxiliary frame in automobile chassis arrangement, the front should as far as possible to bridge near the circumference.

Fig. (12) is for the bulk cement truck tank, auxiliary frame relative to automobile chassis installation position. To meet the axle weight distribution premise, A should not be oversized but could put air compressor cans; B as frame former increase from main frame arch cross rail distance, is in commonly $100 \mathrm{~mm}$ at all; $\mathrm{C}$ is fixed in front of auxiliary frame first $U$ bolt pitch arch beam distance, general control in 500 800 $\mathrm{mm}$ range.

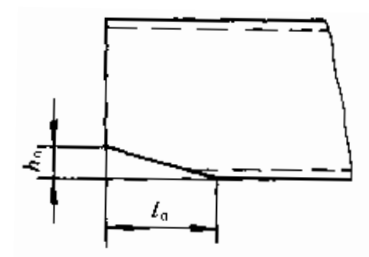

(i)

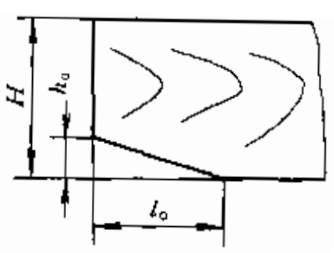

(b) (a) just mass auxiliary frame; (b) hard wood auxiliary frame

Fig. (11). Auxiliary frame front simple shape.

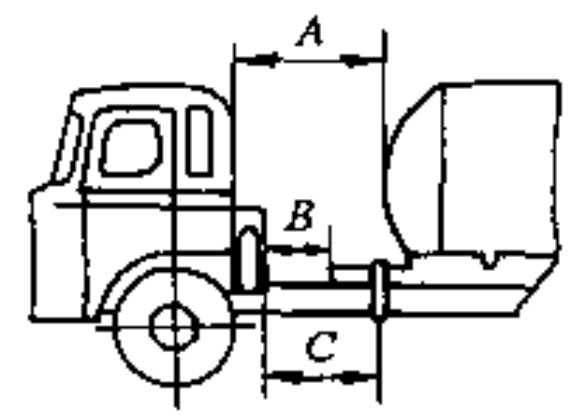

Fig. (12). Auxiliary frame installation position.

\section{CHASSIS STRUCTURE CONNECTION DESIGN}

\subsection{Rail And Beam Connection Design}

Beam and rail connection ways mainly have three kinds, which are shown in Fig. (14).

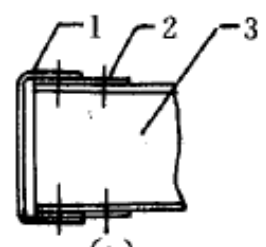

(a)

1 - girder;

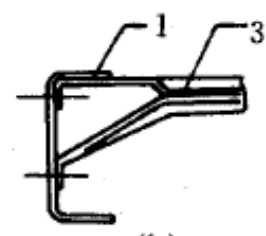

(b)

2 - connecting plate;

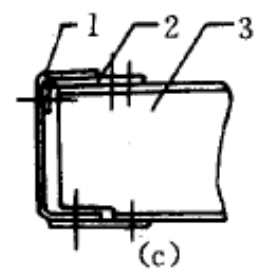

3- beam
Fig. (13). Beam and rail connection.

Fig. (13a) beam and rail are in fluctuation flange connection, the advantage of connection mode is helping improve orsional rigidity of grider. But the defect is when frame generate large torsion deformation, stress of girder fluctuation wing surface will increase, then cause girder fluctuation wing the early damage. Due to the frame ends torsional deformation is little, so the frame ends before and after adopt the connection mode, in order to enhance the girder the torsional rigidity of the longitudinal connection size larger connecting plate. Beam only fixed in the web.

Fig. (13b) beam only fixed on the web, connection stiffiness in this kind of connection form is poor, allow section produce free see song, can be in frame next wing surface deformation by large area, in order to avoid girder fluctuation wing surface early damage.

In Fig. (13c), beam and the girder of the web and next wing plate are linked together, this mode of connection combines two connection characteristics on above, but the force acting on longitudinal beam directly transfer to the beam, the strength demand of the beam the is higher. Because the car balance suspension thrust rod and balance suspension bracket on the two beam connect, therefore, the two beam and rail joint under balanced suspension transfer and vertical force (back) and longitudinal force (traction and braking force).

Integrating considerations all above, this pair of frame girder and the beam will connect in the third way, which means beam and the girder of the web and next wing plate is linked together, at the same time in order to reduce cost and is suitable for the batch production, the frame girder and beam connection will rivet. 


\subsection{Auxiliary Frame And the Main Frame of the Connection Design}

Auxiliary frame and the main frame connection often use few kinds of forms.

\subsubsection{Thrust Connection Plate}

In Fig. (14) is SITAIER heavy special purpose vehicle, it shows the thrust connection plate structure shape and its installation. In the upper, connecting plate end and auxiliary frame fixed through welding, and lower the use bolt and the main frame girder web connection. Advantages of Thrust plate like it can bear larger horizontal load, prevent auxiliary frame and the main frame girder relative horizontal displacement. Adjacent two push thrust connection plate in the distance between 500 1000 $\mathrm{mm}$ range [8,9].

\subsubsection{Connection Support}

Connection support by independent of each other, bottom bracket composition, upper and lower bracket are through the bolt respectively with the auxiliary frame and main frame girder of web phase fixed, and then use bolt will be upper and lower bracket phase connection, like what Fig. (15) shows. Due to the upper and lower brackets have gap in between, so connection support to withstand horizontal load is limited, so the connection support should be thrust connection plate with use. General layout is former suspension support connect with connecting bracket., then the former suspension support connect with thrust bearing connecting plate

\subsubsection{U Clamping Bolt}

When elected to other connecting device have difficulty, can use $\mathrm{U}$ clamping bolt. But in frame, by torsion load maximum range, $U$ type bolt is not adopted. When using $\mathrm{u}-$ bolt fixed, to prevent the main frame girder wing surface deformation, should be in the inside line with wood, must use Angle of lining.

$\sigma_{2 \max }=\frac{H M_{\max }}{2\left(J_{1}+J_{2}\right)} \leq[\sigma]$

Considering the characteristics of three kinds of connecting methods, and assembly technology, this EQ3090 main auxiliary frame is between the thrust connection plates.

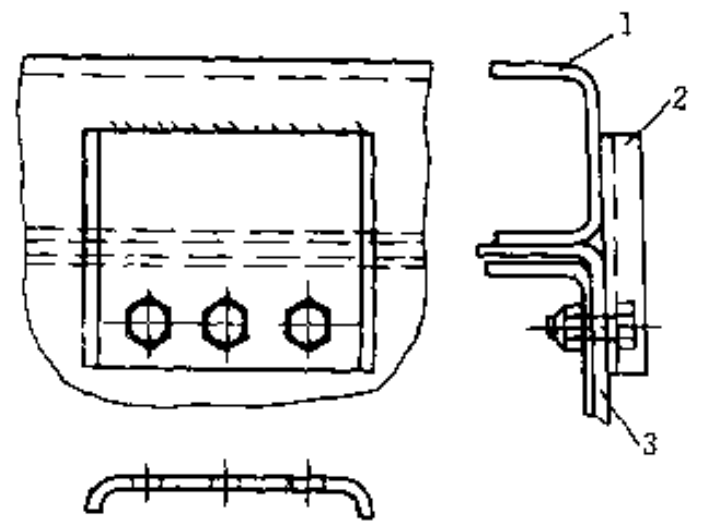

1 - auxiliary frame; 2 - thrust connection plate; 3 - main frame girder

Fig. (14). Thrust connection plate structure.

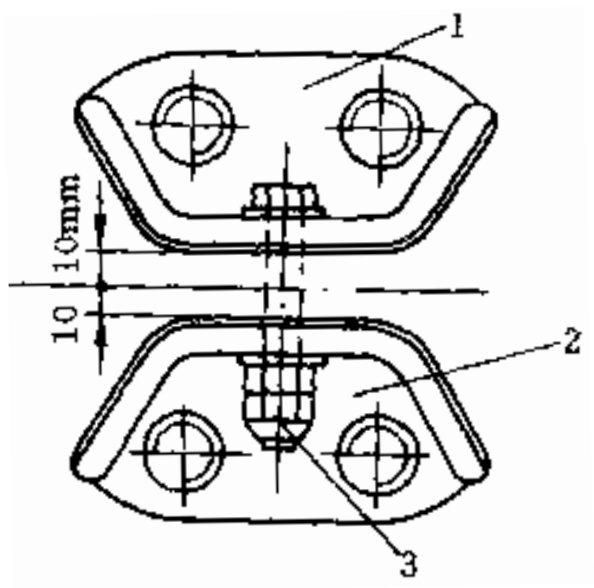

1 - the bracket, 2 - bottom bracket, 3 bolt

Fig. (15). Connection support.

\section{CONCLUSION}

After the modification of the special automobile tire wear uniform; Control stability; Left, right wheel bearing quality equal distribution, the maximum deviation is not more than $3 \% \sim 4 \%$. Through the following way for auxiliary frame for intensity:

If known frame in dangerous working conditions, dangerous section of the bending moment for $M_{\max }$, can calculate the auxiliary frame in dangerous section of the bending moment $\mathrm{M}_{\max }$, namely:

$M_{\max }=J_{2} M_{\max } /\left(J_{1}+J_{2}\right)$

Auxiliary frame of maximum bending stress strength meet the following conditions:

Type, $\mathrm{H}$ - auxiliary frame section height;

$[\sigma]$ - allowable bending stress.

The above refitting meets the requirement, and can satisfy the basic use of occasions.

\section{ABOUT THE AUTHORS}

\section{First Author}

Zhanguo Wei, university lecturer of Central South University of Forestry and Technology. Ph.D. Majoring in Mechanical Engineering Design and Manufacturing.

\section{Second Author}

Zhuoxian Zhou, student of Central South University of Forestry and Technology. Majoring in Mechanical Engineering.

\section{CONFLICT OF INTEREST}

The authors confirm that this article content has no conflict of interest.

\section{ACKNOWLEDGEMENTS}

The authors wish to acknowledge the support by Youth Scientific Research Roundation of Central South University 
of Forestry \& Technology (QJ2011005A) and plan project (postdoctoral scientific research funding project of Hunan 2013RS4049) of Science Department of Hunan Province, China.

\section{REFERENCES}

[1] A. Yuangao, and L. Zhaohui, "Study of automatic view angle transformation for power equipment in the virtual maintenance", International Journal of Digital Content Technology and its Applications, vol. 6, no. 23, pp. 208-215, 2012.

[2] J. Li, Y. Luo, and M. Tian, "The parallel loop filter and nco in the all-digital parallel receiver", International Journal of Digital Content Technology and its Applications, vol. 5, no. 12, pp. 484490, 2011.

[3] Z. Cancan, Q. Junjiang, and Z. Xiaodong, "Agent behavior based modeling and simulation for pricing coordination in supply chain",
Journal of Convergence Information Technology, vol. 7, no. 23, pp. 484-493, 2012.

[4] L.Yang, H. Y. Lang, "Dump truck frame of the static and dynamic calculation and analysis" Journal of Special Purpose Vehicle, vol. 1, pp.23-26, 2006.

[5] C. X. Ming, G.Tong, M.Z.Bin, C.Ping, H. X. Song, "Based on the structural optimization and composite balance of the conventional beam pumping unit energy saving reconstruction", Journal of Daqing Petroleum Institute, vol. 5, pp. 118-120, 2011.

[6] X. Zhang, and Y.H. Ying, "Pumping unit energy saving technology and its development trend", Journal of Oil and Chemical Energy Saving, vol. 2, p. 6, 2007.

[7] Z. Ping, etc, "Pumping unit well high efficiency and energy saving technology", Journal of Foreign Oil Field Engineering, vol. 2, pp. 32-35, 2002.

[8] W.Y. Jiong, "Beam pumping unit crank shaft torque calculation formula analysis", Journal of Petroleum/Machinery, vol. 23, no. 5 pp. 35-42, 1994.

[9] D. Gartman, Auto Opium: A Social History of American Automobile Design, Routeldge, 1994, p. 10.

(C) Wei and Zhou; Licensee Bentham Open.

This is an open access article licensed under the terms of the Creative Commons Attribution Non-Commercial License (http://creativecommons.org/licenses/by-nc/3.0/) which permits unrestricted, non-commercial use, distribution and reproduction in any medium, provided the work is properly cited. 